\title{
Application of Transplantation Technology to Improve Coral Reef Resources for Sustainable Fisheries and Underwater Tourism
}

\author{
Rudy C. Flores, Hermogenes M. Paguia, Romualdo de Guzman, Digna de Guzman, and Nomer N. \\ Varua
}

\begin{abstract}
This paper discusses the partial accomplishments of the countrywide roll-out of coral transplantation and coral nursery establishment using asexually reproduced transplantation materials to improve productivity of coral resources for sustainable fisheries and enhanced underwater tourism. One of the project sites in the country is in Bagac, Bataan, monitored by BPSU under the DOST-PCAARRD. BPSU is also monitoring another site in Subic, Zambales The project aims to aesthetically enhance damaged reef by undertaking coral restoration through transplantation of 25,000 fragments of corals or "corals of opportunities" (COPs) in two sites in Saysain, Bagac, Bataan within the said municipality's Marine Protected Area (MPA) and within the coastal vicinity of Subic Bay, Zambales. The project has deployed 10 Coral Nursery Units (CNU) in Bagac and another 10 in Zambales with 500 COPs per CNU within a period of three months prior to transplantation. Direct transplantation was also conducted to compare results with those planted in CNUs. To date, more than 16,000 COPs have been planted in Bataan and Zambales (May 2015 to January 2016). After the completion of this project, it is envisioned that this will jumpstart coral restoration service industry by developing a pool of human resources for coral restoration and harness the full potential of the resources for underwater tourism and at the same time promoting science-based coral reef management. Pointers for a more successful implementation of the program are recommended.
\end{abstract}

Index Terms-Coral reef restoration, Philippine coral reefs, coral resources, sustainable fisheries, underwater tourism industry, marine research, coral transplantation.

\section{INTRODUCTION}

Coral reef is the most important part of marine ecosystem. It is commonly similar to forest ecosystem that provides habitat, as source of food, shelter and breeding grounds for marine aquatic organisms. Coral also provides balance for nutrient accumulation during rainy season such as, carbon, nitrogen, and phosphate from the terrestrial ecosystem through filtering that contribute to the reduction of fertility of marine waters.

However, in some point these corals were intentionally

Manuscript received December 18, 2015; revised May 18, 2016.

Rudy C. Flores is with Bataan Peninsula State University, Office of Research, Extension and Auxiliary Services, City of Balanga, Bataan, Philippines (e-mail: rcf_abby121970@yahoo.com;).

Hermogenes M. Paguia, Romualdo de Guzman, Digna M. de Guzman, and Nomer N. Varua are with Bataan Peninsula State University, Office of Extension Services, City of Balanga, Bataan, Philippines (e-mail: hmpaguia@gmail.com, nomer_varua@dlsu.edu,phnomer1202@gmail.com). damaged by human activities such as, dynamite fishing, muro-ami and improper anchorage of fishing boats. Where corals were destroyed and this resulted to the decline in fish production where fisher folk fear that they may lost their main livelihood in the area.

Coral reefs have always been considered as one of the most productive ecosystem on earth. There are about 9 million living animals and plants described by Knowlton (2001a) being hosted by coral reefs, thus, it is called the rainforest of the sea [1].

As an archipelagic country, coral reef play a vital role in nation building as it contributes to at least $\mathrm{P} 70$ billion annually to the economy. The World Bank's Philippine Environment Monitor [2] estimated that 1 sq.km. of healthy coral reef generates an average of P n 2.5 million from fishing and tourism. For the latter, the CY 2012 number of leisure dive tourist arrivals multiplied with an estimated expenditure of $\$ 100 /$ day for 3 days could indicate that the Philippines was able to generate $\$ 37.8 \mathrm{M}$ in (DOT-Profile of Visitors in Selected Markets 2010-2012) [3]. The competitive advantage of the Philippines is its rich marine diversity which earned the distinction from Dr. Kent Carpenter, a world-Renowned marine biologist, as being "the center of Marine biodiversity in the world". Table I shows the relatively growing number of leisure dive tourists in the Philippines.

TABLE I: LEISURE DIVE TOURIST ARRIVAL TO THE PHILIPPINES (2010-2012)

\begin{tabular}{|c|c|c|c|}
\hline MARKET & 2010 & 2011 & 2012 \\
\hline Korea & 8,887 & 7,402 & 68,056 \\
\hline United States & $\begin{array}{c}19,80 \\
5\end{array}$ & 9,992 & 12,400 \\
\hline Germany & $\begin{array}{c}18,85 \\
1\end{array}$ & $\begin{array}{c}14,62 \\
5\end{array}$ & 10,724 \\
\hline Australia & $\begin{array}{c}12,68 \\
2\end{array}$ & 8,708 & 8,602 \\
\hline Hong Kong & 6,286 & 2,018 & 8,188 \\
\hline United Kingdom & $\begin{array}{c}12,89 \\
1\end{array}$ & 8,671 & 6,570 \\
\hline Singapore & 2,179 & 1,654 & 2,371 \\
\hline Canada & 5,424 & 3,640 & 2,227 \\
\hline Japan & 1,435 & 375 & 2,062 \\
\hline China & 187 & 1,216 & 1,756 \\
\hline Taiwan & 1,282 & 1,272 & 1,516 \\
\hline Overseas Filipinos & - & - & 1,728 \\
\hline TOTAL & $\begin{array}{c}89,91 \\
1\end{array}$ & $\begin{array}{c}59,57 \\
2\end{array}$ & $\begin{array}{c}126,20 \\
0\end{array}$ \\
\hline
\end{tabular}

Unfortunately, Philippine coral reefs are in serious deterioration and continue to suffer massive decline in abundance, diversity and habitat structure due to anthropogenic activities such as pollution, overfishing, destructive fishing practices using dynamite or cyanide, 
collecting live corals for the aquarium market and mining coral for building. [4]. On the other hand natural factors such as typhoons, cyclones and hurricanes have also contributed to the destruction of coral reefs as these produce strong waves that break apart or flatten large coral heads, and scatter fragments [5]. Braching corals are more vulnerable to storm damages compared with massive forms such as brain coral or the stouter branching forms since the former become unstable as they grow. It is also underscored that a single storm seldom kills off an entire colony, but slow-growing corals may be overgrown by algae before they can recover-a circumstance that may be aggravated by increased nutrient output from runoff and sedimentation.

Taking cognizance of the importance of coral reefs to the economy, several countries have invested in the development of technologies to manage, restore and rehabilitate damage reefs. Over the last 35 years, coral restoration tools have been promoted and applied in several countries as an invaluable tool for reefs have been studied, documented and compared to natural recruitment [6] as a complimentary effort to better manage the said resource. Based on previous studies, it had been observed that the use of coral fragments from donor colonies or from dislodged fragments [7] have the capacity to restart new colonies elsewhere when artificially attached to stable substrate as compared to waiting for new recruits to regrow [8]. In the Philippines, patches of rubble created by blast-fishing have been successfully stabilized using $2-\mathrm{cm}$ plastic mesh laid directly on the rubble and held down with rebar stakes. These patches were at $8 \mathrm{~m}$ depth and relatively sheltered and the stabilization resulted in about 10 times better survival of coral recruits than on adjacent unstabilized rubble reading to a significant increase in coral cover within two years. Rock piles made of reef rock and cement $(0.5 \mathrm{~m} 2$ in area and $1 \mathrm{~m}$ in height) were also placed on the mesh to attract fish and within two years the stabilized areas had fish communities similar to those on adjacent healthy reef in both species composition and biomass [9].

Active reef restoration $\mathrm{R}$ and $\mathrm{D}$ programs/projects under the DOST, commenced in CY 2010 when the University of the Philippines-Marine Science Institute was provided a grant for the "Reef Restoration: Preserving Coral Diversity and Increasing Reef Resilience in the Face of Climate Change Program." It focused on the development of low-cost, effective and transferable technique in coral transplantation for coral conservation, and reef restoration.

As a follow through strategy, the DOST embarked on the fine-tuning and innovation of existing restoration technologies that had been earlier done in other countries. The "Filipinnovation on coral Restoration Program" was able to transplant a total of 227,595 broken fragments or "corals of opportunities (COPs)" with the University of San Carlos (USC), Bicol Univesity-Tabaco, and Mindanao State University-Tawi-Tawi taking the lead in the field testing and validation including the pilot-demonstration of transplantation of "corals of opportunities (COPs) and establishment of coral nursery units (CNUs) in 10 coastal municipalities nationwide. The said Program was also in collaboration with Batangas State University (BSU), Bohol Island State University (BISU), Aklan State University (ASU), Southern Leyte State University (SLSU), and in cooperation with Municipal-LGUs of Baler, Aurora; Bagac, Bataan; Anilao, and San Juan, Batangas; San Fernando, Masbate; Panglao, Bohol; Boracay, Malay and Tangalan in Aklan; Padre Burgos, Southern Leyte; Bongao, Tawi-Tawi and various private sectors including the Sangkalikasan Producers Coop., Boracay Association of Scuba Schools (BASS), Ocean Adventure, etc.

While direct transplantation is still the preferred method for restoration through asexual reproduction, the concept of using coral nurseries, where coral materials are cultured to a size suitable for transplantation, has been steadily gaining recognition [10]. In addition, the CNUs may also ensure the availability of transplantation materials all-year round and abate the cutting/fragmenting from the natural reefs. It is under these premises that under the DOST Filipinnovation on Coral Restoration Program several designs of coral nursery units (CNUs) have been field tested so as to come-up with a design using locally-available materials and would be suitable to local conditions that could yield to higher survival rate than the $65 \%$ target at the onset of the program.

Banking on the gains from the Filipinnovation Program, the DOST is now rolling out two (2) technologies in several coastal municipalities and cities nationwide. These are:

1) Direct transplantation using commercially-available marine putty, nails and plastic cable ties; and

2) Rearing of transplantation materials in the coral nursery units (CNUs)

Roll-out Strategy. Coral restoration is an undertaking that entails a lot of investment with a very long gestation period till the benefits are manifested and realized. As in other countries, the Philippine government is expected to spearhead and to an extent, provide the fund for coral reef rehabilitation and restoration since coral reefs and other living organisms are common pool resources.

On the part of the DOST, its efforts are directed towards the development of appropriate and cost-effective technologies that will enable the government line-agencies and local government units (LGUs) to effectively carry-out their mandates with respect to coral reef management; and, assist the private sector particularly those involved in underwater tourism industry to become more competitive. The DOST's role is to serve as the catalyst and the integrator who will "define the technology, set standards, and subsidize the early adopters" who will help promote the adaptation of the innovations that were generated by the DOST Filipinnovation Program.

Based on the classification of the technology adopters, the USC, BUCF and the MSU-TCTO are the innovators. They were tasked to fine-tune and pilot test existing coral restoration technologies most-likely suitable to local conditions through the use of readily-available materials in the country. Moreover, these institutions are expected to define the limits of the technology and should be able to provide the solutions in case there is a breakdown during its application.

On the other hand, a key group individuals who had earlier collaborated and had been recipients of technology 'know-how' from the innovators are the early technology adopters. They are now in-charge of rolling-out the 2 technologies that had been fine-tuned and field tested in the 
DOST Filipinnovation in Coral Restoration Program. These early adopters did not only undergo classroom and in-situ trainings on coral restoration but have also inputted in technology fine-tuning through the interactions in the course of program implementation.

The early adopters are now in-charge of the ramp-up and roll-out of the foregoing coral transplantation technologies. Being in the tourism business, they will be able to put the commercial application to these technologies for underwater tourism and coral services. Moreover, they are also 1) potential investors for underwater tourism in the restoration sites where very few or no private sector has ventured into; and, 2) potential contractors for coral restoration services.

Together with the DOST, the Bataan Peninsula State University is taking part in the attempt to "cross the chasm" for the mass adoption of the locally-innovated coral transplantation technologies. Once established, the rehabilitation area will also serve as an attraction to recreational and scientific studies on corals and other marine organisms. At the same time, it will result in increase awareness of the community in protecting and preserving their resources for sustainable production of aquatic resources in the province.

Objectives. The general objective of the project is to restore the degraded coral reef of Bagac and Subic to increase marine biodiversity and fishes, and provide livelihood of beach resort owners like recreational diving sites and awareness of the community in protecting and preserving our corals for sustainable development. At this point,

Specifically, the project aims to:

1) Restore the coral reef through establishment of coral nursery unit and transplanting of coral of opportunities to the site identified.

2) Train the concern agencies in the establishment of $\mathrm{CNU}$, Collection of COP's and Transplantation activities through scuba diving training.

3) Establish a 200 square meter coral plantation (100 corals per square meter) on the site identified to be critical at Bataan and another 580 square meter in Zambales.

4) Conduct seminar and trainings on coral restoration for community awareness and sustainable protection and preservation.

\section{Methodology}

The following discusses the methodology or strategies for the implementation of the coral reef rehabilitation project.

\section{A. Pre-project Implementation}

Site Assessment. Two areas which are approximate to each other were identified and assessed for each of the project sites.

Initial Scoping. Consultative dialogue was undertaken with the Municipal Mayor and key municipal personnel, and with potential partners in the project implementation including the private sector. The concept project proposal was implemented and an initial leveling of expectations was carried-out. Also, the dialogue determined the following; a) the status of coral reefs in the municipality, b) LGU and other stakeholders' efforts towards coral reef management including protection; c) areas declared as marine protected areas (MPAs); d) availability of coastal resources management plan and tourism development plan among others. More importantly, this activity sought to secure the buy-in of the municipal LGU into the project since it will play a very critical role in ensuring the success and sustainability of the project

\section{B. Implementation Phase}

Capacity building. Prior to training of personnel who will conduct coral restoration, acquisition of equipment and supplies and materials were done. The training program was two-pronged to commence with scuba diving training and licensing of personnel. For those who already have the scuba diving proficiency and license, they underwent both lecture and hands on training on basic coral biology and restoration.

Presentation to the Town Council and Public Hearings. At the onset of implementation, enabling instruments were secured from the Municipal Sanguniang Bayan since the project site is within the municipal waters; therefore, under the jurisdiction of the Municipal LGUs. Consultation meetings and public hearings with stakeholders were conducted to forge linkages that will eventually ensure cooperation even after the project completion. Said linkages were formalized through a Memorandum of Agreement (MOA) and subsequently, municipal resolutions and ordinances.

Fabrication of coral nursery units (CNUs). CNUs were made of metal angle bars (2" width) with a measurement of $3 \mathrm{~m} \times 1 \mathrm{~m} \times 0.5 \mathrm{~m}$ and with no cement footing for its anchorage (Fig. 1).

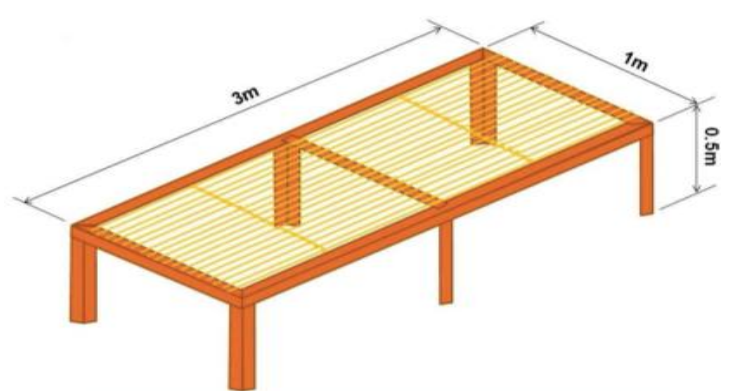

Fig. 1. A coral nursery unit (CNU) specification.

To increase durability of the CNU and prevent the early onset of rust and corrosion, epoxy paint is applied and allowed to set for three days before the CNU can deploy. Once the paint has properly cured, 18 evenly-spaced holes are drilled at both ends of the frame ( $1 \mathrm{~m}$ side). \#8 nylon ropes will be strung through the holes and must be pulled tight and tried at both ends. Tension must be maintained because the ropes will be where the corals would be attached. The combined weight of 500 coral fragments will make the ropes sag if they are not kept taut.

Collections of COPs. COPs were collected/harvested and directly transplanted in the natural reefs or attached in the CNUs where these were reared for at 2-3 months before transplantation so as to allow the healing of lesions obtained from initial fragmentation from mother colony.

The collection site has to have well to excellent coral cover and to ensure availability of COPs for the entire duration of the project and if possible should be $500 \mathrm{~m}$ from CNU site. 


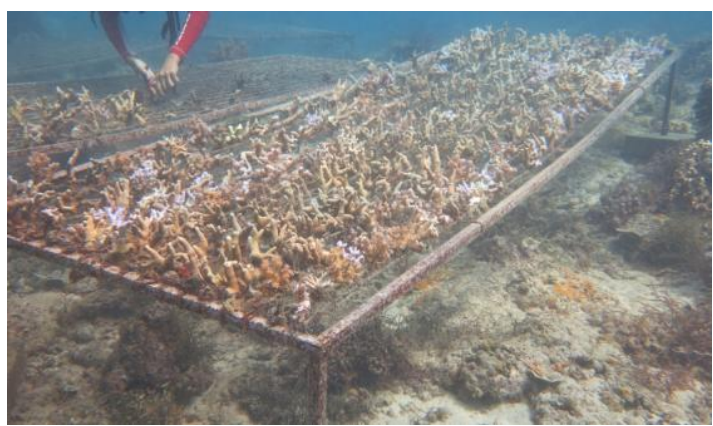

Fig. 2. Rearing of COPs in the coral nursery unit (CNU).

Establishment of coral nurseries. The CNUs were deployed in the identified nursery sites which should be a) $<500$ meters from the collection site, b) sheltered, secured and protected, c) away from run-offs (rivers, industrial, etc.), d) a flat area with sandy bottom and e) with good water quality. Fig. 2 shows an actual $\mathrm{CNU}$ in the rehabilitation site. Collected corals are reared for six months before transplantation in the permanent site.

Each of the CNUs have 500 COPs and periodic cleaning and maintenance were conducted.

Coral Transplantation. The site are coral reefs: a) having as much as possible $60 \%$ - $80 \%$ coral cover, b) 6-15 m (lowest low tide); c) that are easily accessible; d) proximate to hotels/resorts; and ideally inside an MPA and should be declared as a core or no-take zone.

Collected COPs were directly transplanted using commercially-available marine putty, nails and plastic cable ties together with nursery reared transplantation materials.

\section{RESULTS AND DISCUSSION}

By strictly following the technology packaged from the Department of Science and Technology - Philippine Council on Agricultural and Natural Resources Research and Development (DOST-PCARRDD), the following presents the results of the project as of October 2015.

The implementation of the coral reef rehabilitation project.

\section{A. Project Location}

The nature of the project area has 25 to $50 \%$ of the corals were damaged due to dynamite fishing, illegal fishing nets and improper anchorage of small fishing boats through ocular diving activities conducted and these sites were identified to have critical coral reef and need to be restored. The project sites were situated at Floen Resort, Bagac, Bataan and Old Saysayin, Bagac, Bataan as Site 1 and Subic Bay, Zambales for Site 2.

\section{B. Identification of Implementers and Monitoring Team}

The DOST-PCARRD identified the project implementers and monitoring team. The project aims to institutionalize its implementation. The BPSU was identified to monitor the project while the Philippine Army (PA) is assigned for its implementation. There were two (2) monitoring teams that were created by BPSU which includes two (2) focal persons and four (4) members.

On the other hand, there are 20 trained divers from the PA who established the coral nursery units (CNUs) and at the same time they are also assigned for the establishment and collection of COP's including transplantation and protection.

Training of the Monitoring Team. A two-day technology orientation, training and cross-visit was attended by the monitoring team last March 13-14, 2015at Anda de Boracay Resort in the Province of Bohol. The said training-workshop aimed to create the plans and activities of coral transplantation, development of a training module for the stakeholders (Government agencies, NGO and PO's) that will implement and conduct the project. At the same time, the two-day event also gathered the project's technical and content writers for the development of a coffee table book which will contained the accomplishments and success stories of the projects across the country. Its concept and mode of production were discussed to make sure the uniformity in concept and content of the coffee table books across projects sites in the country.

\section{MOA Signing}

The BPSU and DOST-PCARRD signed the Memorandum of Agreement (MOA) last December 2015. High level officials from BPSU and the DOST-PCARRD witnessed the signing of MOA to formalize the project implementation together with the duties and responsibilities of both parties for transparency and legality of the project.

Training of the Implementers and Monitoring Team on Scuba Diving. The 20 selected trainees were trained by the Philippine Association for Underwater Activities (PAUA) for scientific and underwater activities that includes, proper handling of diving equipment, techniques and the collection and planting of COPs. The trainees were represented by Philippine Army, Philippine National Police (PNP) and the DENR. The training lasted for five days from March 24 to 28 , 2015.

On the other hand, same training were conducted by the monitoring team from the BPSU, who were also trained by PAUA from April 16 to April 18, 2015 in Quezon City for Pool Training and then in Anilao and Bauan, Batangas for the actual open water diving training. This enabled the monitoring team to properly monitor on-site the weekly progress of the project and accomplished activities. All the PA, PN, DENR and BPSU personnel who were trained by PAUA were granted the One-Star Open Diver license.

\section{Establishment of CNUs, COP Collection and Tagging}

After the training on scuba diving, the implementers (Philippine Army) set up 5 CNU's from the first site located in Floen Beach resort and is located about $1 \mathrm{~km}$ away from the shore with the depth of $20 \mathrm{ft}$. The establishment of CNU in the first site together with collection of COPs and tagging was from March 9 to May 6, 2015.

Five CNU's was also installed in the second site situated at Old Saysayin, Bagac, Bataan which is also $1 \mathrm{~km}$ away from the shore. This second site is very proximate to the first site for practical reasons and because the sites are contained within the Marine Protected Area (MPA).The installation, collection and tagging of CNUs for the second site started on May 19 and ended on June 11.

The COP collection sites were from 500 meters away from the 2 CNU's with the depth of 20 feet. Table II shows the initial collection and tagging of COPs during the 
establishment of the first batch of CNUs.

TABLE II: COLLECTION AND TAGGING OF COPS

\begin{tabular}{|c|c|}
\hline Collection and Tagging of COPs & Date \\
\hline Tag 1 & March 9-April 6 \\
\hline Tag 2 & April 7 - April 13 \\
\hline Tag 3 & April 14 - April 21 \\
\hline Tag 4 & April 22 - April 28 \\
\hline Tag 5 & April 29- May 6 \\
\hline Tag 6 & May 19- May 23 \\
\hline Tag 7 & May 14 - May 28 \\
\hline Tag 8 & May 29- June 1 \\
\hline Tag 9 & June 2 - June 5 \\
\hline Tag 10 & June 7 - June 11 \\
\hline
\end{tabular}

\section{E. Monitoring of the Project}

The monitoring of the project was weekly or every other week, and depending on weather condition for safety of the divers. The two CNUs were established on March 28, 2015. Collection, tying, and tagging of CNUs were from March 29 to June 12,2015 . The average fragments planted for every $\mathrm{CNU}$ is about 500 coral fragments with a total of 5,000 fragments planted in the $10 \mathrm{CNUs}$. The survival rate and growth rate of the COPs are yet to be determined because as of writing of this paper, he monitoring team is yet to dive and measure but were unable to monitor because of the unfavorable weather condition.

Inventory Activities from the CNUs. Every $\mathrm{CNU}$ was regularly monitored as per date of planting and evaluated the number of fragments planted per CNUs. The numbering of the CNUs from 1 to 10 are based from the first date of planting up to the last fragments for every CNU. The earliest date planted CNU was numbered 1 up to the last date of planting which was number 10 .

Tagging (Fig. 3) was also undertaken for every line of the CNUs with the use of colored fastener. These are numbered with roman numerals to determine the mortality for every line per CNU. Documentation of mortality per CNUs were also undertaken every other week to observe the growth of the corals. At the same time, identify the causes of mortality of the latter. Data regarding this is not yet available as the monitoring team is yet to gather data. Data gathering is delayed because of unfavorable weather not suitable for diving.

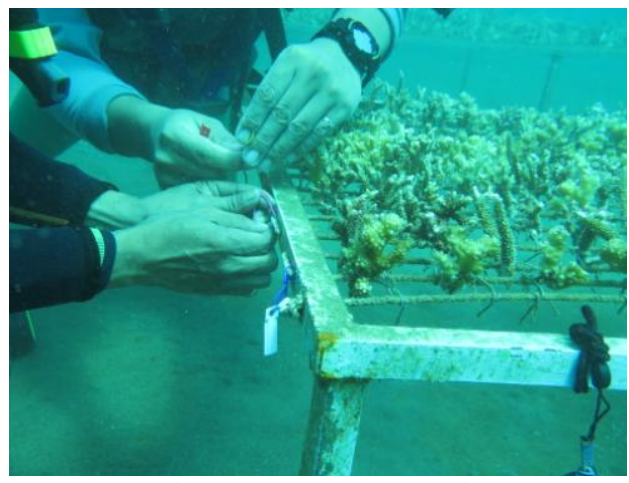

Fig. 3. Tagging of COPs for monitoring purposes of survival rate in the coral nursery units (CNUs).

Direct Transplantation of Coral Fragments. The direct transplantation (Fig. 4) was conducted to test if the coral fragments will give a higher percentage of survival. An area was established for direct transplantation for newly collected coral fragments. These are located 10 to $15 \mathrm{~m}$ meters near the established CNUs. A 5 inch concrete nails were with a prepared 4 to 5 inches height coral fragment tied with the concrete nail using a plastic strap so that the fragment will stay in place. The area established was $500 \mathrm{~m}$ away from the CNUs with an average depth of 20ft. Fig. 5 shows a batch of COPs directly transplanted in a substrate. The branching out of corals indicated positive growth and survival.

\section{F. Key Project Indicators}

As of January 2016, there is a total transplanted area of 540sqm which totals to more than 13,500 coral fragments successfully transplanted in Bataan and almost 3,000 COPs transplanted in Zambales occupying 120sqm. The target transplanted corals in Bataan area is 20,000 fragments, while the target in Zambales are 5,000 COPs transplanted. The COPs reared in the $10 \mathrm{CNUs}$ in Bagac totals to 5,000 coral fragments, 2,000 of which are already transplanted while the remaining was destroyed by typhoons that hit the area in August and September 2015. The other 1,000 plus COPs were directly transplanted after collection. To date, the project has accomplished $66 \%$ of the total target of transplanted COPs in both areas. The project is set to be completed by end of March 2016. Based on the initial sampling of some COPs in the area, the average growth of COPs is $3 \mathrm{~cm}$.

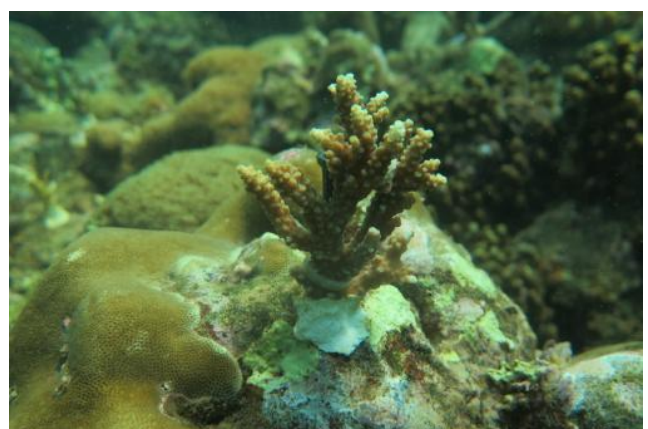

Fig. 4. A COP transplanted in a substrate. The COP is secured with a concrete nail, cable tie, and marine epoxy.

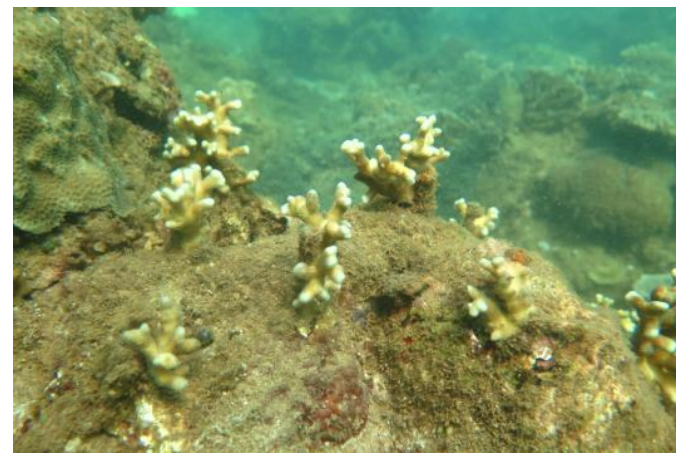

Fig. 5. A group of COP within a quadrant transplanted six (6) months ago. The COPs have shown significant growth of $6 \mathrm{~cm}$ on the average.

\section{SUMmARY AND CONCLUSION}

In overall, the project site in Bataan and Zambales is faring well. The Coral Nursery Units are still intact and are well in placed, with new batch of COPs being reared in the nurseries. Although some challenges on the administrative aspect of the project implementation are encountered, it does not have significant impact on the utilization of technology being implemented in the site. The implementation and monitoring 
are important parts of the project in order to ensure that the line-up activities were religiously taken. The following were the lesson learned by both implementers and monitoring tea: 1) Training and seminars on planning and development of coffee table book, scuba diving, coral transplantation and coordination makes the implementation ensures a well and proper management of activities; 2) Coordination among implementers and monitoring team through distance communication provides a better understanding on the duties and responsibilities of each group. At the same time, problems met were well taken into considerations to improve the program of activities of the project; and 3) Regular or weekly monitoring was the key to address problems on the development of the site and instill sense of commitment and understanding between the implementers and monitoring team on the main objectives of the project.

Based on the initial project implementation and monitoring, the following preliminary recommendations were drawn:

1) Training and seminars are important tools in the implementation of the project in order to develop the necessary skills for better project implementation.

2) Development of IEC materials that provide awareness of the communities in order for them to protect and preserve their marine resources for sustainability should be started.

3) Regular monitoring of project will improve understanding in the different activities undertaken for development.

4) Communication is one factor that will enhance participation of both team player and ensure transparency on the project implemented.

\section{ACKNOWLEDGMENT}

The authors wish to thank the Department of Science and Technology - Philippine Council on Agriculture and Aquatic Resources Research and Development (DOST-PCAARRD), the Sangkalikasan Producers Cooperative, the Local Government of the Municipality of Bagac, BataanUNTV News Agency, and the Bataan Peninsula State University.

\section{REFERENCES}

[1] N. Knowlton, "Ecology: Coral reef biodiversity - Habitat size matters," Science, vol. 5521, pp. 1493-1495, 2001.

[2] World Bank. (2005). Philippines environment monitor 2005: Coastal and marine resource management. Washington, DC: World Bank. [Online].

Available: http://documents.worldbank.org/curated/en/2005/12/7129749/philipp ines-environment-monitor-2005-coastal-marine-resource-managemen $\mathrm{t}$

[3] Department of Tourism, "Positioning the Philippines as the dive center of Asia," presented at the 12th Philippine Travel Exchange, September 2013.

[4] M. A. Palma, M. Tsamenyi, and W. R. Edeson, "Promoting sustainable fisheries: The international legal and policy framework to combat illegal, unreported and unregulated fishing," Boston, Mass.: Martinus Nijhoff Publishers, 2010

[5] Hughes et al., "Climate change, human impacts, and the resilience of coral reefs," Science, vol. 301, pp. 929-933, 2003.

[6] T. J. Goreau and W. Hilbertz, "Marine ecosystem restoration: costs and benefits for coral reefs," World Resource Review, vol. 17, no. 3, pp. 375-409, 2005

[7] D. S. Gillian, "Southeast Florida coral reef evaluation and monitoring project 2003: Year 1 report," Florida Fish and Wildlife Conservation Commission, Florida Marine Research Institute, pp. 1-11, 2004.
[8] W. C. Jaap, "Coral reef restoration," Ecol Eng, vol. 15, no. 13-4, pp. 345-364, 2000.

[9] N. A. J. Graham, K. M. Chong-Seng, C. Huchery, F. A. Januchowski-Hartley, and K. L. Nash, "Coral reef community composition in the context of disturbance history on the great barrier reef, Australia," PLoS ONE, vol. 9, no. 7, p. e101204, 2014.

[10] B. Rinkevich, "Conservation of coral reefs through active restoration measures: Recent approaches and last decade progress," Environmental Science and Technology, vol. 39, no. 12, pp 4333-4342, 2005.

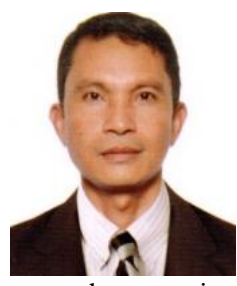

Rudy C. Flores was born in Tucop, Dinalupihan, Bataan, Philippines on December 19, 1970. He obtained his bachelor of agricultural technology degree at Ramon Magsaysay Technological University in 1992, his master of science in agriculture degree at Pampanga State Agricultural University in 1997. He is a Ph.D. in agricultural sciences candidate and currently the vice-president of research, extension and auxiliary services of Bataan Peninsula State University, City of Balanga, Bataan, Philippines. He specializes in agricultural researches. He is also involves in various agriculture, fisheries and natural resources researches and developmental activities in the Philippines. Mr. Flores is the Battalion Sgt Major of the 1st Bataan Ready Reserve Battalion, ARESCOM, Philippine Army from 2004 to present. He is a member of the Philippine Association of Agriculturists, Inc. (PAA) and elected as the vice-president of the PAA Central Luzon Chapter. He is also a member of the International Society for Southeast Asian Agricultural Sciences (ISSAAS), the Philippine Association of Research Managers, Philippine Society of Animal Science, Philippine Association of Extension Program Implementers and the Philippine Agricultural Economics Development Association

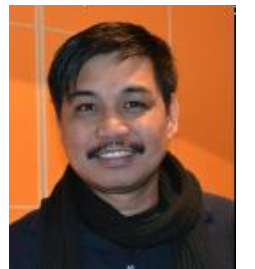

Hermogenes M. Paguia presently serves as the director of extension services at the Bataan Peninsula State University. Already a veterans in the research and extension field, Dr. Paguia has been active in research presentations in both national and international levels. A graduate of BS of animal science, Dr. Paguia has spearheaded numerous projects within his capacity and under the funding of the Philippines Department of Science and Technology - Philippine Council of Agriculture and Aquatic Resources Research and Development (DOST-PCAARRD). He was one of the World Outstanding Researchers recognized by the International Association on Multidisciplinary research. Dr. Paguia was also a recipient of a fellowship in Holland.

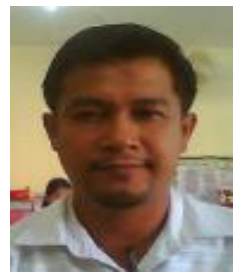

Romualdo de Guzman is currently the associate director for extension services at the BPSU Abucay Campus and currently serving as the coordinator for the university's agriculture and forestry programs. He finished his master of science degree at the Central Luzon State University.

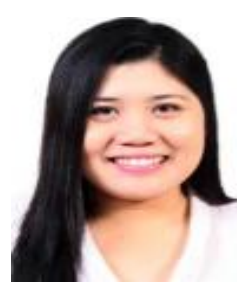

Digna M. de Guzman holds the associate director for extension at the BPSU Orani Campus and is currently serving as a member of the University's Gender and Development (GAD) Committee and University Faculty Association. She is currently taking up her master's in social work at the University of the Philippines in Diliman.

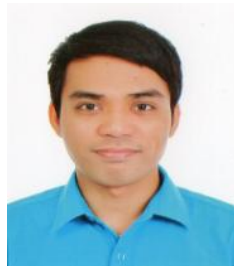

Nomer N. Varua is the BPSU Office of Extension Services' Applied Communications Specialist in charge of producing information, education and communication materials. He is currently writing his dissertation for the degree of doctor of philosophy in applied linguistics at De La Salle University in Manila, the Philippines. 